\title{
Down-regulation of the caffeic acid O-methyltransferase gene in switchgrass reveals a novel monolignol analog
}

Timothy J Tschaplinski ${ }^{1,5^{*}}$, Robert F Standaert ${ }^{1,5,6}$, Nancy L Engle ${ }^{1,5}$, Madhavi Z Martin ${ }^{1,5}$, Amandeep K Sangha ${ }^{1,5,6}$, Jerry M Parks ${ }^{1,5}$, Jeremy C Smith ${ }^{1,5,6}$, Reichel Samuel ${ }^{2,5}$, Nan Jiang ${ }^{2,5}$, Yunqiao Pu ${ }^{2,5}$, Arthur J Ragauskas ${ }^{2,5}$, Choo Y Hamilton ${ }^{1,5}$, Chunxiang Fu ${ }^{3,5}$, Zeng-Yu Wang ${ }^{3,5}$, Brian H Davison ${ }^{1,5}$, Richard A Dixon ${ }^{4,5}$ and Jonathan R Mielenz ${ }^{1,5}$

\begin{abstract}
Background: Down-regulation of the caffeic acid 3-O-methyltransferase EC 2.1.1.68 (COMT) gene in the lignin biosynthetic pathway of switchgrass (Panicum virgatum) resulted in cell walls of transgenic plants releasing more constituent sugars after pretreatment by dilute acid and treatment with glycosyl hydrolases from an added enzyme preparation and from Clostridium thermocellum. Fermentation of both wild-type and transgenic switchgrass after milder hot water pretreatment with no water washing showed that only the transgenic switchgrass inhibited C. thermocellum. Gas chromatography-mass spectrometry (GCMS)-based metabolomics were undertaken on cell wall aqueous extracts to determine the nature of the microbial inhibitors.

Results: GCMS confirmed the increased concentration of a number of phenolic acids and aldehydes that are known inhibitors of microbial fermentation. Metabolomic analyses of the transgenic biomass additionally revealed the presence of a novel monolignol-like metabolite, identified as trans-3, 4-dimethoxy-5-hydroxycinnamyl alcohol (iso-sinapyl alcohol) in both non-pretreated, as well as hot water pretreated samples. iso-Sinapyl alcohol and its glucoside were subsequently generated by organic synthesis and the identity of natural and synthetic materials were confirmed by mass spectrometric and NMR analyses. The additional novel presence of iso-sinapic acid, iso-sinapyl aldehyde, and iso-syringin suggest the increased activity of a para-methyltransferase, concomitant with the reduced COMT activity, a strict meta-methyltransferase. Quantum chemical calculations were used to predict the most likely homodimeric lignans generated from dehydration reactions, but these products were not evident in plant samples.

(Continued on next page)
\end{abstract}

\footnotetext{
*Correspondence: tschaplinstj@ornl.gov

'Biosciences Division, Oak Ridge National Laboratory, Oak Ridge, TN 37831-6341, USA

${ }^{5}$ BioEnergy Science Center, Oak Ridge, TN 38731, USA

Full list of author information is available at the end of the article
} 
(Continued from previous page)

Conclusions: Down-regulation of COMT activity in switchgrass resulted in the accumulation of previously undetected metabolites resembling sinapyl alcohol and its related metabolites, but that are derived from para-methylation of 5-hydroxyconiferyl alcohol, and related precursors and products; the accumulation of which suggests altered metabolism of 5-hydroxyconiferyl alcohol in switchgrass. Given that there was no indication that iso-sinapyl alcohol was integrated in cell walls, it is considered a monolignol analog. Diversion of substrates from sinapyl alcohol to free iso-sinapyl alcohol, its glucoside, and associated upstream lignin pathway changes, including increased phenolic aldehydes and acids, are together associated with more facile cell wall deconstruction, and to the observed inhibitory effect on microbial growth. However, iso-sinapyl alcohol and iso-sinapic acid, added separately to media, were not inhibitory to C. thermocellum cultures.

Keywords: trans-3, 4-Dimethoxy-5-hydroxycinnamyl alcohol, iso-Sinapyl alcohol, Monolignol, Switchgrass, Bioenergy, Recalcitrance, Caffeic acid O-methyltransferase, Transgenic

\section{Background}

There are three well known monolignol precursors that polymerize to form the lignin that binds plant cell walls together: $p$-coumaryl alcohol, coniferyl alcohol, and sinapyl alcohol. These result, respectively, in the hydroxyphenyl $(\mathrm{H})$, guaiacyl $(\mathrm{G})$, and syringyl $(\mathrm{S})$ monomer units of the lignin polymer. The relative proportion of monolignols can determine the ease of cell wall deconstruction by enzymatic or biocatalyst-mediated mechanisms [1]. For example, the ratio of $S$ to $G$ residues, the most abundant monolignols in angiosperms, can impact the degree of cross-linking of the lignin, the degree of condensation, and hence, the spatial arrangement and accessibility of the lignin to deconstruction [2-4]. The polymerization of these monolignols and their crosslinking with phenolic acids to hemicellulosic sugars are keys to the recalcitrance of cell walls to enzymatic hydrolysis that is required to release sugars for biofuel production. High $\mathrm{S} / \mathrm{G}$ ratios are considered favorable for deconstruction in angiosperms [5], but the reverse is true for alfalfa, tall fescue and switchgrass [1,6,7]. In some cases, lignin content appears to be more predictive of recalcitrance than does lignin composition [1]. The contents of lignin and ether-bound phenolics in the cell wall were the major determinants of the biomass degradation caused by enzymatic hydrolysis in Miscanthus genotypes [8]. Other studies also suggest that either lignin content or composition can play a role in sugar release from cell walls of grasses and trees, including Miscanthus [9] and Populus [10].

Down-regulation of the caffeic acid 3-O-methyltransferase EC 2.1.1.68 (COMT) gene in the lignin biosynthetic pathway of switchgrass (Panicum virgatum) produced transgenic plants with a normal growth phenotype, but with reduced lignin content, altered lignin composition, improved forage quality, increased saccharification efficiency, and increased ethanol production yield from the modified substrate compared with the controls [7]. Two of the COMT-deficient lines from this study had greatly reduced COMT expression levels versus the wild-type genetic background. Interestingly, there was a decline in the S/G ratio of cell walls of stems from 0.90 to 0.57 , with $\mathrm{S}$-lignin specifically reduced by up to $53 \%$, and an overall decline in acetyl bromide lignin content of $12-14 \%$, depending on the transgenic line. These responses imply a reduction of trans-sinapyl alcohol in these transgenic lines. Whereas the down-regulation of COMT may or may not result in a reduction in lignin content, it generally results in a reduction of $\mathrm{S}$ units in a variety of plant species lignin, including hybrid poplar (Populus tremula $x$ alba) [11], alfalfa (Medicago sativa) [12], maize (Zea mays) [13], Arabidopsis thaliana [14], and tall fescue (Festuca arundinacea) [15]. Whereas S-units are typically reduced, G units may also be reduced, but to a lesser extent, thereby still resulting in the often reported increase in the S/G ratio of the lignin. Such a coupled reduction in both $S$ and $\mathrm{G}$ units in response to down-regulation of COMT was observed in alfalfa [12] and in perennial ryegrass (Lolium perenne) [16]. Also frequently observed is a concomitant increase in the precursor 5-hydroxyguaiacyl units that are derived from the incorporation of 5hydroxyconiferyl alcohol into transgenic lignin, as reported for the brown-rib mutant $(b m r 3)$ in maize with reduced COMT activity [17], in COMT-deficient hybrid poplar [18], and in the Arabidopsis Atomt1 mutant $[14,19]$. Given such responses, broad effects on the metabolic network beyond the targeted transgenic manipulation should be expected.

Curiously, the COMT-deficient switchgrass residues that remain after mild pretreatment inhibit fermentation by the bacterium Clostridium thermocellum, compared to the wild-type switchgrass plants. Given that the COMT-deficient lines contain a genetic block in the lignin pathway [7], it was hypothesized that these plants have a reduced concentration of sinapyl alcohol and contain increased concentrations of phenolic aldehydes and acids related to the lignin biosynthetic pathway that 
are inhibitory molecules for biological processes [20]. We used gas chromatography-mass spectrometry (GCMS)based metabolomic profiling of pretreated (hot water) biomass of down-regulated COMT switchgrass (Panicum virgatum) lines to reveal the greater presence of such inhibitory phenolic metabolites, and, in particular, a novel monolignol-like metabolite identified as trans-3, 4-dimethoxy-5-hydroxycinnamyl alcohol (iso-sinapyl alcohol) and related metabolites that accumulate in transgenic COMT-deficient switchgrass lines. The general consequences of the present findings for consolidated bioprocessing and switchgrass engineering for biofuel production are discussed.

\section{Results}

\section{Bacterial fermentation of transgenic COMT-deficient versus wild-type switchgrass}

In contrast to the previously mentioned published research with acid-soaked, pretreated switchgrass, which requires washing to remove acid, the unwashed waterpretreated transgenic switchgrass solids failed to ferment fully, compared to the wild-type switchgrass. These results come from experiments comparing the impact of milder pretreatment conditions on the transgenic COMT down-regulated and wild-type switchgrass variety 'Alamo', used previously with more severe pretreatment [7], in conjunction with fermentation by $C$. thermocellum. Pretreatment was conducted on watersoaked switchgrass at $180^{\circ} \mathrm{C}$ for 25 minutes. Specifically, the wild-type yielded total fermentation products (lactic acid, acetic acid, ethanol) at $208.1 \pm 2.8 \mathrm{mg}$ total products/g cellulose, while the transgenic COMT-deficient switchgrass, which was the same line used [7], had essentially the same yield on substrate of $196.8 \pm 20.5 \mathrm{mg}$ total products/g cellulose. These results were unexpected as the same samples had yielded up to $38 \%$ more ethanol per gram cellulose for the COMT transgenic switchgrass vs. the wild-type biomass, using a yeastbased simultaneous saccharification and fermentation process with the washed, acid pretreated samples. The reduced yield by the transgenic switchgrass suggested an inhibition of fermentation not seen with previous samples of the free liquid available after hot water pretreatment.

\section{Metabolomic profiles of hydrolysates of COMT down-regulated versus wild-type switchgrass}

There were unexpected responses in metabolomic profiles resulting from GCMS-based analyses of aqueous extracts of the mild water pretreated biomass of transgenic COMT down-regulated and wild-type switchgrass variety 'Alamo'. The key changes in metabolomic profiles resulting from the down-regulation of COMT are shown in Table 1. Responses that are unrelated to the lignin biosynthetic pathway, but were nonetheless outstanding in COMT down-regulated plants, included the accumulation of purine bases and their corresponding nucleosides. For example, a number of purines and pyrimidines, including adenine, guanine, uracil, hypoxanthine and xanthine, were increased 1.4- to 2.7-fold. Associated nucleosides, including uridine and guanosine, were also elevated 1.6 to 2.4-fold, respectively, but adenosine was unchanged. Several organic acids, including maleic, citraconic, and succinic acids, were similarly increased 1.6-2.6-fold. Such unexpected responses in pathways remote from the targeted pathway can be challenging to explain.

The fundamental target of reducing the production of trans-sinapyl alcohol was achieved as expected by down regulation of the caffeic acid 3-O-methyltransferase, with the concentration in the transgenic lines reduced to $72 \%$ of that of the wild-type control. This was confirmed by similar reductions in related metabolites, including the conjugation product syringin (sinapyl alcohol glucoside; $77 \%)$, syringaresinol (52\%), a lignan, and syringylglycerol (67\%), a related wall degradation catabolite, and its glycoside (50\%). Another abundant wall degradation catabolite, guaiacylglycerol, and glycosidic conjugates were similarly reduced in COMT down-regulated plants. These latter metabolites are, however, related to coniferyl alcohol, the other major monolignol precursor. Pinoresinol, a lignan of coniferyl alcohol, was also reduced to $49 \%$ that observed in the wild-type lines. These responses contrast with increases in the major phenolic aldehyde related to coniferyl alcohol, vanillin that increased 1.56-fold. Similarly, phenolic acids related to coniferyl alcohol, including ferulic acid and 5-hydroxyferulic acid, were also increased 1.3and 1.7-fold, respectively, and 1-O-trans-feruloylglycerol was also elevated 1.4-fold. An unknown compound eluting at $15.18 \mathrm{~min}$ (338 354 mass-to-charge ratio; $\mathrm{m} / \mathrm{z}$ ) that shares $\mathrm{m} / \mathrm{z}$ with ferulic acid, and hence may be a conjugate, was evident only in transgenic plants. Another unidentified lignan (RT $15.09 \mathrm{~min}, 239354620 \mathrm{~m} / \mathrm{z}$ ) was also only evident in COMT down-regulated plants. Many of these phenolic aldehydes, acids, and lignans are major microbial growth and fermentation inhibitors. Despite the increases in coniferyl alcohol-related phenolic aldehydes and acids, and declines in the aforementioned related wall metabolites, the monolignols, coniferyl alcohol and 5hydroxyconiferyl alcohol, and upstream phenolic acid precursors, including $p$-coumaric acid and caffeic acid were unchanged (which contrasts with the decline in sinapyl alcohol). Although 5-hydroxyconiferyl alcohol was unchanged, its precursor, 5-hydroxyconiferaldehyde was increased 1.28-fold, and its 4-O- and 5-O-glucosides were 76-fold and 60-fold higher, respectively, in the COMT down-regulated lines, with concentrations albeit low for even these plants. 
Table 1 Metabolite concentrations [mean (sem)] and fold change of down-regulated COMT versus wild-type (WT) switchgrass

\begin{tabular}{|c|c|c|c|c|}
\hline Metabolite & COMT concentration $(\mu \mathrm{g} / \mathrm{ml})$ & WT concentration $(\mu \mathrm{g} / \mathrm{ml})$ & COMT/WT fold change & P-value \\
\hline iso-sinapyl alcohol & $0.83(0.06)$ & nd & $\infty$ & 0.000 \\
\hline iso-sinapic acid & $0.11(0.01)$ & nd & $\infty$ & 0.000 \\
\hline 15.09354239620 lignan $^{\text {a }}$ & $0.34(0.02)$ & nd & $\infty$ & 0.000 \\
\hline 15.18354219 M + 530 (iso-sinapyl-phenolic) & $0.11(0.01)$ & nd & $\infty$ & 0.000 \\
\hline 5-hydroxyconiferyl alcohol-4-O-glucoside & $0.08(0.01)$ & $0.00(0.00)$ & 76.05 & 0.000 \\
\hline 5-hydroxyconiferyl alcohol-5-O-glucoside & $0.17(0.01)$ & $0.00(0.00)$ & 59.83 & 0.000 \\
\hline iso-syringin & $2.60(0.32)$ & $0.06(0.01)$ & 42.79 & 0.000 \\
\hline 12.37428327209413 & $0.39(0.02)$ & $0.03(0.01)$ & 14.09 & 0.000 \\
\hline 3,4-dihydroxybenzoic acid & $7.52(3.72)$ & $1.19(0.34)$ & 6.34 & 0.096 \\
\hline xanthine & $1.14(0.14)$ & $0.43(0.18)$ & 2.68 & 0.019 \\
\hline hypoxanthine & $2.85(0.96)$ & $1.07(0.17)$ & 2.65 & 0.080 \\
\hline succinic acid & $14.98(3.97)$ & $5.78(1.04)$ & 2.59 & 0.041 \\
\hline guanosine & $5.18(0.76)$ & $2.17(0.62)$ & 2.39 & 0.018 \\
\hline uracil & $2.02(0.29)$ & $0.98(0.22)$ & 2.07 & 0.023 \\
\hline citraconic acid & $2.25(0.18)$ & $1.23(0.31)$ & 1.82 & 0.033 \\
\hline guanine & $7.24(0.28)$ & $4.10(0.85)$ & 1.77 & 0.016 \\
\hline 5-hydroxyferulic acid & $0.46(0.01)$ & $0.27(0.02)$ & 1.69 & 0.000 \\
\hline uridine & $11.86(0.49)$ & $7.27(1.39)$ & 1.63 & 0.026 \\
\hline maleic acid & $65.92(1.63)$ & $41.74(7.23)$ & 1.58 & 0.023 \\
\hline vanillin & $26.20(1.63)$ & $16.81(3.48)$ & 1.56 & 0.060 \\
\hline secoisolariciresinol & $2.27(0.13)$ & $1.47(0.38)$ & 1.54 & ns \\
\hline 5-oxo-proline & $116.72(6.82)$ & $77.40(7.46)$ & 1.51 & 0.007 \\
\hline adenine & $10.19(0.72)$ & $7.25(0.91)$ & 1.41 & 0.045 \\
\hline 1-O-trans-feruloylglycerol & $1.05(0.05)$ & $0.77(0.11)$ & 1.37 & 0.065 \\
\hline ferulic acid & $7.06(0.17)$ & $5.50(0.14)$ & 1.28 & 0.000 \\
\hline 5-hydroxyconiferaldehyde (13.08 M + 338323 ) & $0.26(0.02)$ & $0.20(0.01)$ & 1.28 & 0.029 \\
\hline adenosine & $9.62(0.66)$ & $7.58(0.86)$ & 1.27 & ns \\
\hline p-coumaric acid & $21.80(0.21)$ & $19.31(0.57)$ & 1.13 & 0.08 \\
\hline caffeic acid & $0.58(0.04)$ & $0.53(0.04)$ & 1.11 & ns \\
\hline p-hydroxybenzaldehyde & $4.63(0.33)$ & $4.24(0.80)$ & 1.09 & ns \\
\hline coniferyl alcohol & $3.34(0.10)$ & $3.65(0.22)$ & 0.92 & ns \\
\hline 5-hydroxyconiferyl alcohol & $1.22(0.06)$ & $1.36(0.08)$ & 0.90 & ns \\
\hline coniferyl aldehyde & $0.35(0.01)$ & $0.45(0.07)$ & 0.78 & ns \\
\hline guaiacylglycerol & $5.25(0.23)$ & $6.79(0.53)$ & 0.77 & 0.047 \\
\hline sinapyl aldehyde & $0.17(0.02)$ & $0.22(0.03)$ & 0.77 & ns \\
\hline syringin & $0.23(0.01)$ & $0.30(0.03)$ & 0.77 & 0.093 \\
\hline sinapyl alcohol & $2.51(0.06)$ & $3.48(0.20)$ & 0.72 & 0.004 \\
\hline$\underline{\text { syringylglycerol }}$ & $2.99(0.09)$ & $4.48(0.25)$ & 0.67 & 0.001 \\
\hline p-hydroxyphenylpyruvic acid & $0.63(0.05)$ & $0.96(0.09)$ & 0.65 & 0.021 \\
\hline guaiacylglycerol glycoside (14.51297608 593) & $3.53(0.17)$ & $5.57(0.69)$ & 0.63 & 0.038 \\
\hline syringaresinol & $0.07(0.00)$ & $0.14(0.01)$ & 0.52 & 0.001 \\
\hline guaiacylglycerol glycoside (14.57 297608 593) & $3.59(0.19)$ & $5.98(0.88)$ & 0.60 & 0.050 \\
\hline syringylglycerol glycoside (16.12 327361 239) & $3.91(0.22)$ & $7.88(1.34)$ & 0.50 & 0.035 \\
\hline pinoresinol & $0.22(0.03)$ & $0.45(0.07)$ & 0.49 & 0.031 \\
\hline guaiacylglycerol glycoside (15.87 297361323 ) & $7.42(0.30)$ & $17.96(4.41)$ & 0.41 & 0.073 \\
\hline hydroxymethylfurfural & $0.72(0.12)$ & $3.40(1.41)$ & 0.21 & ns \\
\hline
\end{tabular}

${ }^{a}$ Metabolites in italics are tentative identifications. 


\section{Identification of iso-sinapyl alcohol and its glucoside}

The transgenic COMT down-regulated samples additionally accumulated two novel peaks that resembled sinapyl alcohol and its 4-O-glucoside, syringin, but both peaks eluted earlier than expected. Analysis with a Waters GCT Premier accurate mass gas chromatograph-time-of-flight-mass spectrometer indicated that the molecular formula of the unknown monomer was identical to that of sinapyl alcohol. Generation of the cis-isomer following a $24 \mathrm{~h}$ exposure of a trans-sinapyl alcohol commercial standard to UV-light (254 $\mathrm{nm}$ ) confirmed that the sinapyl alcohol-like peak was not simply the cis-isomer of the normally observed transmetabolite, with the cis-isomer eluting earlier than the unidentified peak. Given the relative retention time (RT) of the unknown peak, it was hypothesized that the monomer was methylated at the O-4 position on the phenyl ring, instead of the O-5 position, as in sinapyl alcohol. To test this hypothesis, the isomeric monolignol was synthesized. The two-step synthesis (Figure 1a) involved a Wittig reaction between 3, 4-dimethoxy-5-hydroxybenzaldehyde and carbethoxymethylene triphenylphosphorane, followed by reduction of the resulting cinnamate ester with diisobutylaluminum hydride (DIBAL), as described by [21]. The product is named 3, 4-dimethoxy-5-hydroxycinnamyl alcohol (or simply iso-sinapyl alcohol). NMR (Figure 2b) confirmed the structure of the synthetic material, and its GCMS fragmentation pattern and RT (Figure 2) both confirmed the identity of the unknown monomer and the synthetic product. Additionally, we synthesized the 3-O-glucoside (iso-syringin) that also matches the RT and fragmentation pattern of the previously unknown peak (Figure 3). Given that iso-syringin co-eluted with secoisolariciresinol, which contains a trace amount of $\mathrm{m} / \mathrm{z} 354$, quantification of iso-syringin suggests that COMT down-regulated switchgrass has at least 43-fold more of the glucoside than the wild-type plants. Therefore, iso-sinapyl alcohol and iso-syringin were essentially only detected in transgenic plants. To confirm that the presence of iso-sinapyl alcohol was not an artifact of the hot water pretreatment, non-pretreated samples were additionally analyzed. Whereas there was no iso-sinapyl alcohol detected in the non-pretreated wild-type sample, the transgenic plant had $0.28 \mu \mathrm{g} / \mathrm{ml}$ iso-sinapyl alcohol, similar to the $0.29 \mu \mathrm{g} / \mathrm{ml}$ detected in the hot water pretreated sample. Similarly, 3, 4dimethoxy-5-hydroxycinnamic acid (iso-sinapic acid) was also only detected in transgenic plants $(0.11 \mu \mathrm{g} / \mathrm{ml})$. It should be noted that iso-sinapyl aldehyde was detectable in transgenic plants (RT 13.06), but not at quantifiable levels. The accumulation of iso-sinapyl alcohol is accompanied by the production of its glucoside, isosyringin, which was 11.3 -fold higher than syringin in the transgenic plants. The structures of the observed iso-sinapyl alcohol related metabolites and potential synthesis routes are shown in Figure 4.

\section{Quantum chemical calculations of iso-sinapyl radical spin density and reaction thermochemistry}

An interesting question regarding the novel monolignol analog is its ability to participate in oxidative couplings with itself. To assess the intrinsic reactivity of iso-sinapyl alcohol in relation to other monolignols, quantum chemical calculations were carried out using density functional theory with the $\omega \mathrm{B} 97 \mathrm{X}-\mathrm{D}$ functional. Specifically, electron spin densities were computed to determine the distribution of unpaired spin in the iso-sinapyl radical, which indicates relative reactivity at each site, and reaction enthalpies were computed to determine the thermodynamic favorability for various potential radical conjugation reactions. See Additional file 1 for optimized geometries for isosinapyl alcohol and the iso-sinapyl radical, structures and optimized geometries of iso-sinapyl homodimers. The electron spin density is defined as the total electron density of electrons of one spin minus the total density of the electrons of the opposite spin. For radical species, sites with the highest spin densities are, in general, expected to be the most reactive [22,23]. The resulting spin density distributions show that, consistent with resonance arguments, the iso-sinapyl radical has a lower number of possible sites for conjugation than does the sinapyl radical (Figure 5). For the sinapyl radical, the
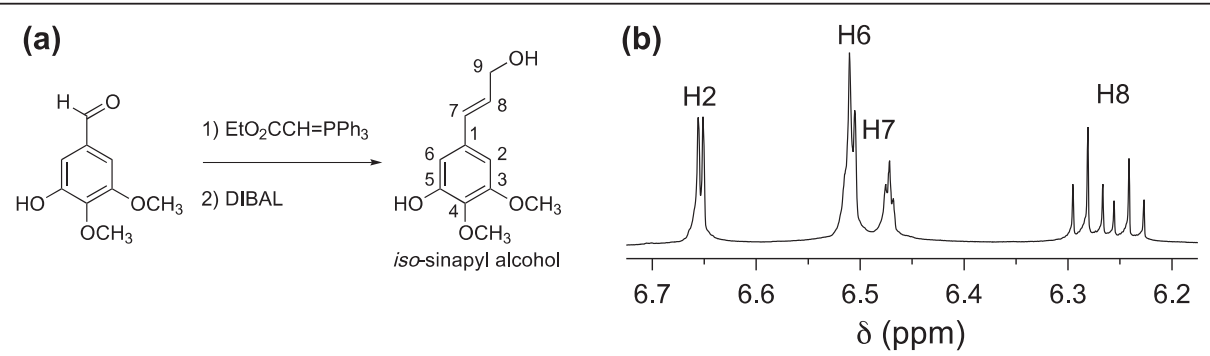

Figure 1 (a) Synthesis of trans-3,4-dimethoxy-5-hydroxycinnamyl alcohol (iso-sinapyl alcohol). (b) ${ }^{1} \mathrm{H}$ NMR spectrum of synthetic iso-sinapyl alcohol (aromatic and double-bond region). 


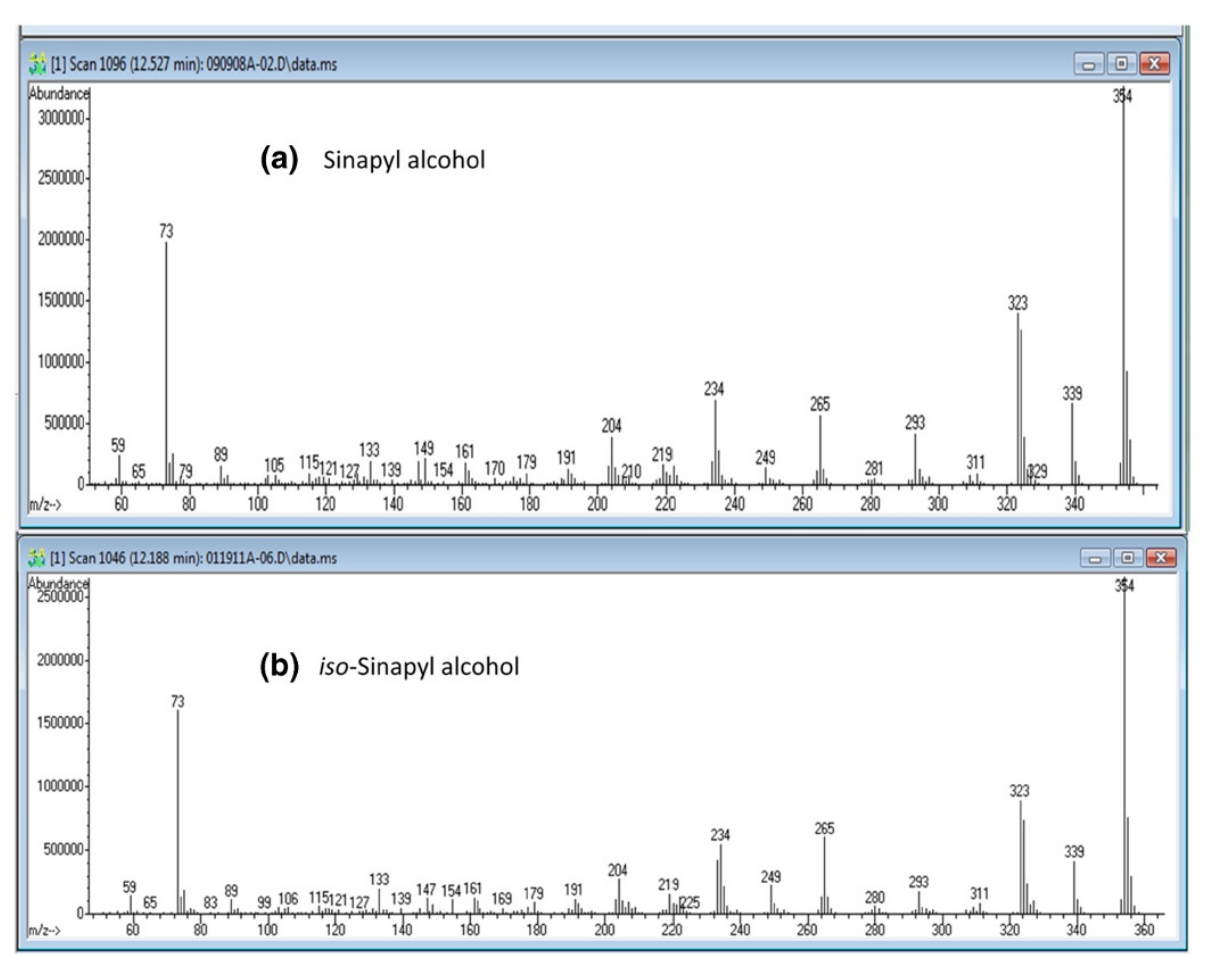

Figure 2 GCMS El fragmentation pattern of trimethylsilyl derivatized a) sinapyl alcohol and synthetic b) iso-sinapyl alcohol.

spin density is highest at $\mathrm{C} 1$, followed by $\mathrm{O} 4, \mathrm{C} 3, \mathrm{C} 8$ and $\mathrm{C} 5$. However, reactivity is expected primarily at $\mathrm{O} 4$ and $\mathrm{C} 8$ because the other positions are sterically hindered by non-hydrogen substituents. In contrast, for the iso-sinapyl radical, the unpaired spin resides predominantly on $\mathrm{O} 5, \mathrm{C} 6, \mathrm{C} 2$ and $\mathrm{C} 4$, with the highest spin density localized at C4 (Figure 5). C4 in iso-sinapyl alcohol is sterically hindered by a methoxy group and is therefore expected to have low reactivity. Furthermore, $\mathrm{C} 8$ is deficient in unpaired spin compared to standard monomer radicals because resonance with the $\mathrm{O} 5$ radical site has been abolished. Therefore, the iso-sinapyl radical is not expected to undergo coupling at $\mathrm{C} 8$.
It is of interest to consider the expected regioselectivity for reactions of the iso-sinapyl radical in the context of lignin polymerization. With highest spin density at $\mathrm{O} 5$ and reaction at $\mathrm{C} 8$ precluded, reaction at $\mathrm{O} 5$ is expected to predominate in couplings of the iso-sinapyl radical. The major linkage type in switchgrass lignin is $\mathrm{O}-8$ [24]. In reaction with a conventional lignol radical partner, the directionality of this linkage is enforced to be $\mathrm{O}$ (iso-sinapyl)-8(partner). Further chain growth would necessarily occur on the partner side, and isosinapyl moieties would thus occur more frequently at chain termini. In reaction of iso-sinapyl radical with a growing chain, reaction via $\mathrm{O} 5$ would preclude extension from the iso-sinapyl group, and one might expect to

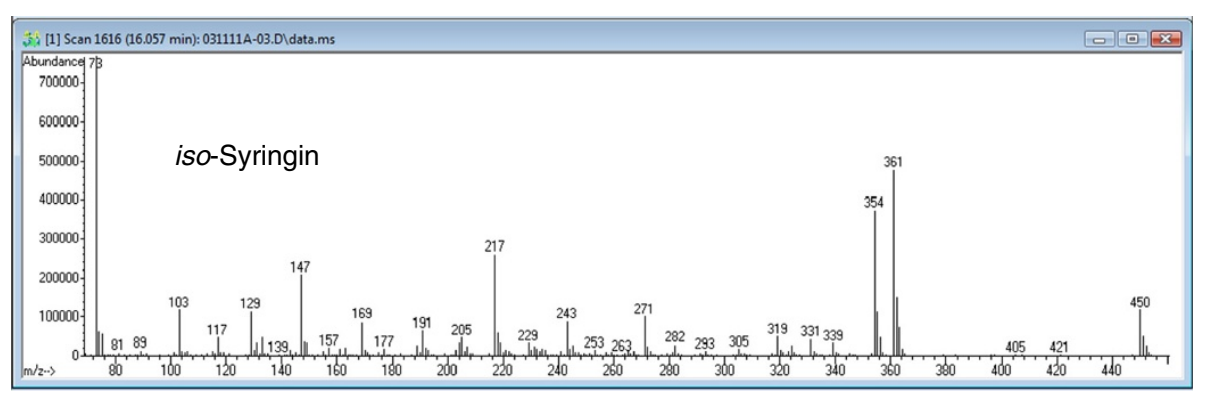

Figure $3 \mathrm{GCMS}$ electron ionization (70 eV) fragmentation pattern of trimethylsilyl derivatized synthetic 3, 4-dimethoxy-5hydroxycinnamyl alcohol-5-O-glucoside (iso-syringin). 


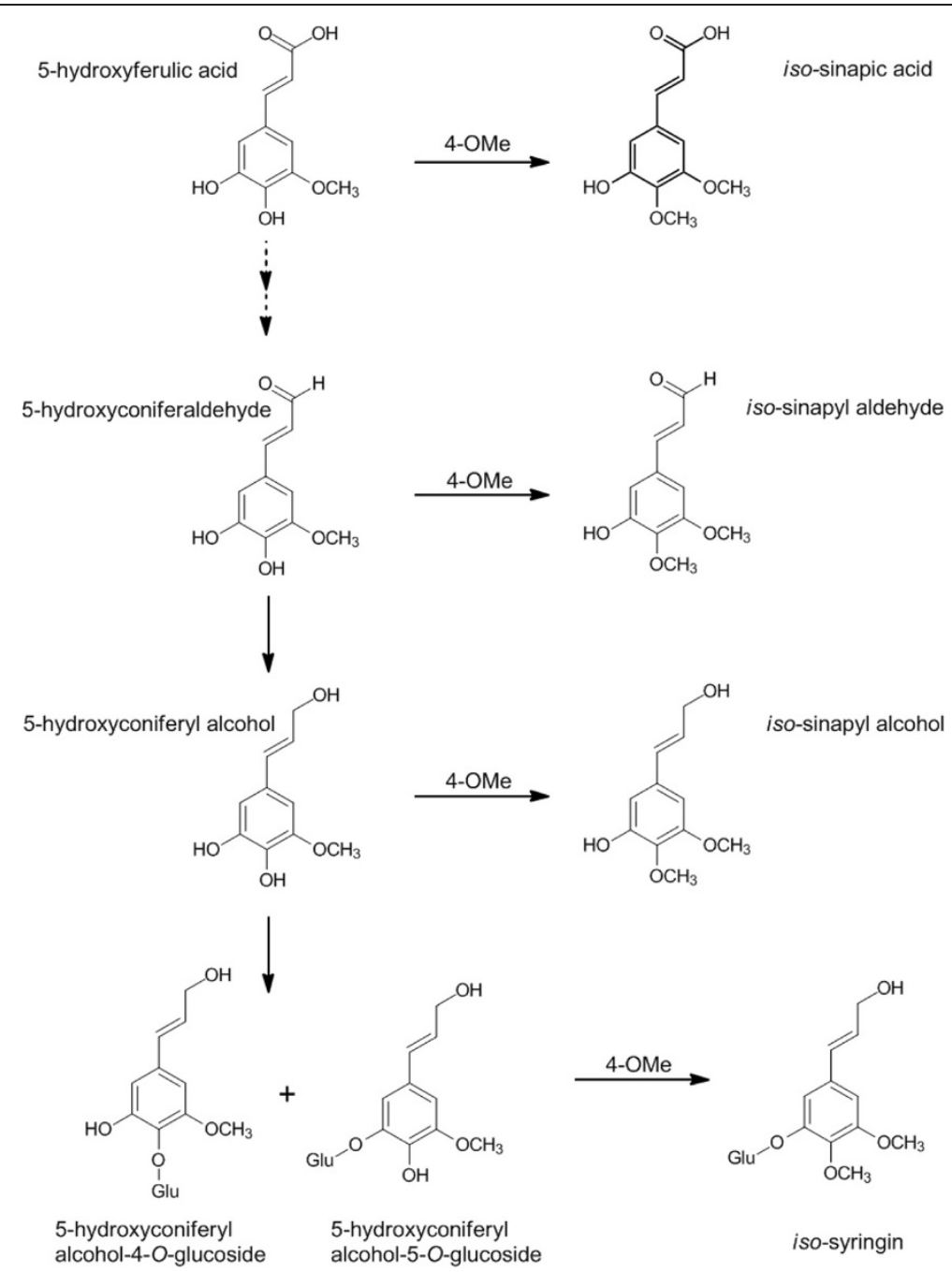

Figure 4 The structures of the observed iso-sinapyl alcohol related metabolites and potential synthesis routes.

see single-unit iso-sinapyl appendages on the chain. Continued growth at the penultimate residue would be possible, but might be impeded where preferred extension sites had been consumed in reaction with iso-sinapyl radical. Overall, one would expect to find iso-sinapyl units relatively enriched at chain termini and as single-unit branches. One might expect a reduced degree of polymerization. However, the GPC analysis indicated that the presence of iso-sinapyl alcohol did not affect the molecular weight of synthetic lignins produced by horseradish peroxidase-catalyzed dehydrogenative polymerization of coniferyl alcohol or sinapyl alcohol (Table 2).

Thermochemistry of iso-sinapyl radical coupling reactions Based on the spin density calculations and steric considerations, two iso-sinapyl radicals could potentially undergo coupling to form $\mathrm{C} 6-\mathrm{O}^{\prime}, \mathrm{C} 6-\mathrm{C}^{\prime}, \mathrm{C} 6-\mathrm{C} 2^{\prime}$ and $\mathrm{C} 2-\mathrm{C} 2^{\prime}$ linked lignans. These preferred couplings were determined from reaction enthalpies calculated for the coupling of two iso-sinapyl radicals to form homodimers (self-coupling). Each of these self-coupling reactions is strongly exothermic, with the $\mathrm{C} 6-\mathrm{C} 2$ ' linked lignan computed to have the most favorable reaction enthalpy $(-40.9 \mathrm{kcal} / \mathrm{mol})$, followed by $\mathrm{C} 2-\mathrm{C} 2^{\prime}(-37.2 \mathrm{kcal} / \mathrm{mol})$, C6-C6' $(-35.7 \mathrm{kcal} / \mathrm{mol}), \mathrm{C} 2-\mathrm{O}^{\prime}(-35.2 \mathrm{kcal} / \mathrm{mol})$ and $\mathrm{C} 6-\mathrm{O}^{\prime}(-31.2 \mathrm{kcal} / \mathrm{mol})$. From in-vitro coupling experiments, the $\mathrm{C} 6-\mathrm{C}^{\prime}$ and $\mathrm{C} 6-\mathrm{O}^{\prime}$ linked lignans were found to be the most abundant, with lower observed production of $\mathrm{C} 6-\mathrm{C} 2{ }^{\prime}$ and $\mathrm{C} 2-\mathrm{C} 2{ }^{\prime}$ linked lignans and no $\mathrm{C} 2-\mathrm{O}^{\prime}$ linked lignans detected. Thus, the experimentally observed products are consistent with calculations in that they are all predicted to result from highly exothermic reactions at sites with high spin density.

\section{Generation of homodimeric lignans of iso-sinapyl alcohol}

We hypothesized that the novel monolignol analog and/ or its lignan dimers may also be a contributing causal 

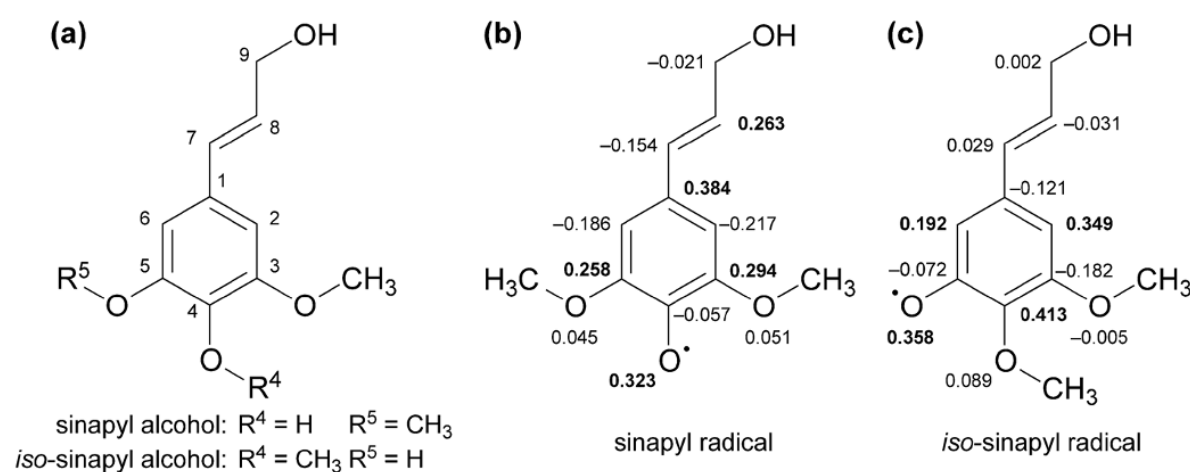

Figure 5 (a) Chemical structures with atom numbering for sinapyl and iso-sinapyl alcohols. Spin density calculations for (b) sinapyl and (c) iso-sinapyl radicals. Potential coupling sites for iso-sinapyl radical are C2, C4, 05 and C6. In comparison to sinapyl radical, iso-sinapyl has one less coupling site and lacks reactivity at C8 in particular.

factor to the microbial inhibitory response, given that a number of lignans were observed to be elevated in the hydrolysates of COMT down-regulated switchgrass. To test this hypothesis a number of known lignans were analyzed and a set of dehydrogenation reactions were undertaken with iso-sinapyl alcohol to generate homodimeric lignans to test for their presence in the genetically modified biomass. Four homodimeric lignans of isosinapyl alcohol were readily synthesized by single dehydrogenation reactions (Figure 6). The $\mathrm{C}^{-}-\mathrm{C6}^{\prime}$ dimer and the $\mathrm{C} 6-\mathrm{O}^{\prime}$ dimer (numbering atoms as in sinapyl alcohol) were the most abundant, whereas there was much less of the $\mathrm{C} 6-\mathrm{C} 2^{\prime}$ dimer and the $\mathrm{C} 2-\mathrm{C} 2^{\prime}$ dimer. These products were expected from the quantum calculations above, but none of these lignans generated from iso-sinapyl alcohol has been confirmed in the COMT down-regulated switchgrass.

\section{Discussion}

Plant species have long been known to contain three major monolignols, p-coumaryl alcohol, coniferyl alcohol, and sinapyl alcohol [5], and more recently 5-hydroxyconiferyl alcohol has been identified as an additional monolignol that can be incorporated into cell walls, particularly in COMTdeficient poplar (Populus tremula $x$ alba) [18]. However, 5-hydroxyconiferyl alcohol remains a relatively minor component of natural lignin, and these results indicated that monolignols other than the three major monolignols can

Table 2 Horseradish peroxidase-catalyzed dehydrogenative polymerization of sinapyl alcohol (SA) or coniferyl alcohol (CA) with iso-sinapyl alcohol (iso-SA)

\begin{tabular}{lccc}
\hline Monomer & Yield (\%) & $\left.\bar{M}_{\mathrm{n}} \mathbf{( 1 0}^{\mathbf{2}}\right)$ & $\overline{\mathbf{M}}_{\mathrm{w}} / \overline{\mathrm{M}}_{\mathrm{n}}$ \\
\hline $\mathrm{SA}$ & 39.2 & 6.3 & 1.3 \\
\hline $\mathrm{SA}+$ iso-SA & 47.7 & 6.7 & 1.5 \\
\hline CA & 67.1 & 11.3 & 1.8 \\
\hline CA + iso-SA & 62.1 & 11.1 & 1.4 \\
\hline
\end{tabular}

be incorporated into lignin. Although 5-hydroxyconiferyl alcohol was not affected in the present study, its 4-O- and 5-O-glucosides were greatly accumulated (76-fold and 60fold, respectively) in COMT down-regulated switchgrass lines. Here, we also demonstrate that the down-regulation of COMT loci in switchgrass additionally resulted in the accumulation of a novel monolignol-like metabolite, isosinapyl alcohol, its glucoside, iso-syringin, and related metabolites iso-sinapic acid and iso-sinapyl aldehyde. The presence of iso-sinapyl alcohol in non-pretreated samples of transgenic plants negates the potential argument that it is an artifact of the mild, hot water pretreatment as a breakdown product of benzodioxane $(\beta-\mathrm{O}-5, \alpha-\mathrm{O}-5)$ substructures, which can form from cross-coupling reactions involving radicals of 5-hydroxyconiferyl alcohol. If the latter were the case, iso-sinapyl alcohol should be evident in both wild-type and transgenic plants, given that both plant types have at least small quantities of 5-hydroxyconiferyl alcohol. iso-Sinapyl alcohol has previously been isolated from the roots of Ferula sinaica [25], the leaves of Croton xalapensis L. (Euphorbiaceae) [26], and the feces of the beetle Naupactus bipes [27]. However, it has not been associated with lignin metabolism, it has not been synthesized previously, its biosynthesis in plants has not been investigated, and it has not been previously identified in any of the many previous COMT knockdown studies thus far. It is ironic that blocking of a major methylation step that generates a dimethoxycinnamyl alcohol leads to the appearance of an alternative, novel dimethoxycinnamyl alcohol. A simple explanation for the biosynthesis of iso-sinapyl alcohol would be that the reduced activity of COMT allows another methyltransferase to methylate the para (4-hydroxyl) position on the aromatic ring of the accumulating sinapyl alcohol precursors. Although this hypothesis lacks experimental support with respect to the presence of such a protein(s) being overexpressed, the accumulations of 5-hydroxyferulic acid, 5-hydroxyconiferaldehyde, and 5-hydroxyconiferyl alcohol glucosides provide metabolite evidence that the global 


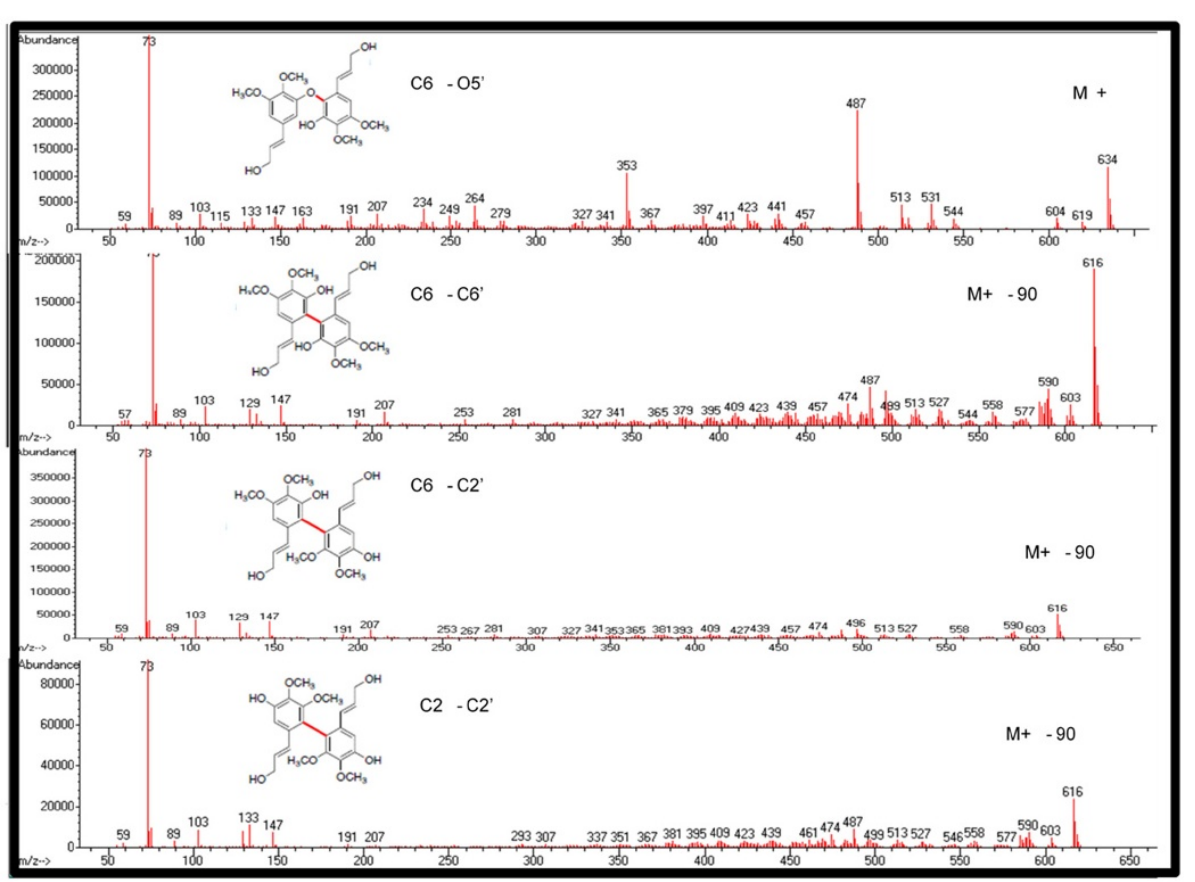

Figure 6 GCMS El fragmentation pattern of trimethylsilyl derivatized homodimeric lignans of iso-sinapyl alcohol. "M+" denotes the molecular ion.

COMT knockdown employed in this study resulted in the accumulation of metabolites that can all be methylated at the para position to produce all of the putative iso-sinapyl alcohol related precursors observed in this study. Given that native COMT specifically methylates the meta (3hydroxyl and 5-hydroxyl) positions on the phenyl ring of aromatic acids/aldehydes and is precluded from substitution at the para position, it is possible that an alternative para-specific methyltransferase, similar to iso-eugenol 4-Omethyltransferase (IEMT; EC 2.1.1.146), described by [28], is able to para methylate the accumulating substrates, including the 5-hydroxyferulic acid, 5-hydroxyconiferaldehyde and/or 5-hydroxyconiferyl alcohol, or there may be an alternate pathway that emerges that generates iso-sinapic acid and results in the reductive formation of iso-sinapyl alcohol. It is generally accepted that COMT acts on 5hydroxyconiferaldehyde/alcohol as substrates, which explains the reduced level of S-residues in mutants and transgenics with reduced COMT activity. Given that 4coumarate-CoA ligase EC 6.2.1.12 (4CL) does not display much activity toward sinapic acid in grasses, there would be limited flux of sinapic acid towards sinapyl alcohol in grasses. Thus, iso-sinapyl alcohol synthesis from iso-sinapic acid was not anticipated, suggesting the aforementioned para-methylation of multiple substrates may be the more likely mode of synthesis of the iso-sinapyl alcohol related metabolites. Although not readily detected in wild-type plants, it cannot be unequivocally stated that this direct synthesis pathway of iso-sinapic acid to iso-sinapyl alcohol doesn't exist in such plants at very low flux and metabolite concentrations. We have detected iso-sinapic acid (0.04 $\mu \mathrm{g} / \mathrm{ml}$ ) in another lignin pathway enzyme (ferulate-5hydroxylase EC 1.14.-.-; F5H) knockdown line in switchgrass, but iso-sinapyl alcohol was not detected in that line. Furthermore, 4-O-methylation of monolignol precursors has been postulated in another monocot species, Vanilla planifolia, although no enzymatic basis for this conclusion has yet emerged [29]. Additional tracer studies are needed to clarify metabolite flux and the primary pathway leading to the production of iso-sinapyl alcohol.

iso-Sinapyl alcohol is a monolignol based on its molecular structure, but a key question remains as to whether it is incorporated into the plant cell wall. Quantum chemical calculations demonstrate a reduced number of conjugation sites for iso-sinapyl alcohol compared to sinapyl alcohol. The most likely homodimeric lignans formed from single dehydration reactions were predicted to be coupled at $\mathrm{C} 6-\mathrm{C} 2^{\prime}$ (based on atom numbering of sinapyl alcohol), $\mathrm{C} 2-\mathrm{C} 2{ }^{\prime}, \mathrm{C} 6-\mathrm{C}^{\prime}$, and $\mathrm{C} 6-\mathrm{O}^{\prime}$, and these were confirmed by organic synthesis, but none was detected in plant samples. However, two lignan-like metabolites were detected only in COMT down-regulated plants that may be iso-sinapyl alcohol-based lignans, but they remain unidentified. A 5-hydroxconiferyl alcoholconiferyl alcohol heterodimeric benzodioxane structure in the lignin of COMT-deficient Populus has been identified [30]. An analogous (benzodioxane) metabolite (5hydroxconiferyl alcohol-sinapyl alcohol), reported by 
[18,31], may be the lignan RT 15.09 min (molecular ion $\left(\mathrm{M}^{+}\right)$620, key m/z 510420 235), which co-elutes with another lignan that is unique to COMT-deficient plants with key m/z 620239354323 265, the latter three m/z are typical of iso-sinapyl alcohol/sinapyl alcohol and suggest the peak may be an iso-sinapyl alcohol heterodimeric lignan. However, this has yet to be verified. Another COMTdeficient unique lignan occurred at RT $15.18 \mathrm{~min}\left(\mathrm{M}^{+} 530\right.$ 219354 ) and is likely an iso-sinapyl alcohol-phenolic acid conjugate. The generation of such lignans following pretreatment suggests that iso-sinapyl alcohol may be a wall component, but we have not found any evidence to support this. Furthermore, the hypothesis that incorporation of the novel monolignol may result in a lower degree of polymerization of the lignin molecule, was not supported from the GPC analysis. It can be concluded that the presence of iso-sinapyl alcohol did not affect the molecular weight of lignin produced by horseradish peroxidase catalyzed dehydrogenative polymerization of either coniferyl alcohol or sinapyl alcohol. In addition, the yield and degree of polymerization $\left(\mathrm{DP}_{\mathrm{n}}\right)$ are slightly lower than the literature report [32], in which a larger scale of HRPcatalyzed DHP of sinapyl alcohol in the presence of sodium azide was carried out $(0.5 \mathrm{mmol}$ sinapyl alcohol: isolated yield: $54.2 \% ; \overline{\mathrm{M}}_{\mathrm{n}} / \overline{\mathrm{M}}_{\mathrm{w}}$ : 1.3; DPn : 4.4). Furthermore, a follow-up analysis of the presence of iso-sinapyl alcohol in transgenic COMT-deficient switchgrass biomass that had water-soluble constituents removed, followed by sequential enzymatic saccharification with fungal (Trichoderma reesei) enzymes, followed then by exposure to cellulolytic microbes Caldicellulosirupter bescii, C. obsidiansis, and $C$. thermocellum, indicated that no iso-sinapyl alcohol was detected in the culture supernatants, whereas sinapyl alcohol, coniferyl alcohol, and 5-hydroxyconiferyl alcohol were present. We conclude that iso-sinapyl alcohol is not a major cell wall constituent and should be considered a monolignol analog, given its structure and coupling propensities. This explains the lack of evidence of cell wall structures derived from iso-sinapyl alcohol in the present study, whereas we were able to detect benzodioxane substructures by HSQC NMR of internode 1 biomass of switchgrass, as has often been reported in COMTdeficient plants $[18,29,32]$. Although not detectable in wild-type plants, these substructures constituted $11 \%$ of the total lignin linkages, similar to the $12 \%$ observed in COMT-deficient Arabidopsis [19], and 10\% in COMT antisense Populus [18]. It should be noted that despite the number of previous studies of various plants species with reduced COMT activity e.g., [15,18,30,33], iso-sinapyl alcohol has not been previously identified in such plants, nor has it been identified with the lignin biosynthetic pathway. However, given the associated occurrence of iso-sinapic acid, iso-sinapyl aldehyde, upstream precursors from the lignin pathway, including 5-hydroxyferulic acid and 5- hydroxyconiferaldehyde, accumulation of glucosides of 5hydroxyconiferyl alcohol, we conclude that the metabolite flux associated with 5-hydroxyconiferyl alcohol production and subsequent metabolism differs in switchgrass from the other species previously characterized. The accumulation of 5-hydroxyconiferyl alcohol related precursors and glucoside conjugates, provide the substrates that can then be methylated at the para- position on the aromatic ring to generate iso-sinapyl alcohol and related metabolites. The production of iso-sinapyl alcohol and its glucoside, iso-syringin, may be non-specific detoxification processes. Other species that have lower rates of production of 5-hydroxyconiferyl alcohol or greater flux of 5-hydroxyconiferyl alcohol into cell walls don't permit the accumulation of the substrates that would lead to iso-sinapyl alcohol production, and hence, a possible explanation for the lack of their detection in previous studies.

The evidence of reduced recalcitrance to deconstruction processes recently reported by [7] may be related to the additional metabolite responses associated the appearance of iso-sinapyl alcohol, namely the increased incorporation of phenolic acids of the lignin pathway, particularly ferulic acid, 5-hydroxyferulic acid, and ferulic acid-glycoside conjugates. These changes result in the reduced $p$-coumaric acid to ferulic acid ratio that has been associated with increased forage digestibility in six barley lines [34], but, paradoxically, increased recalcitrance in switchgrass [35]. In monocots, such as corn, the $p$-coumaric acid in secondary cell walls is thought to be bound to lignin, whereas ferulic acid serves as a bridge between lignin and hemicellulose [36]. Sophisticated re-engineering of the cell walls by monolignol substitution with methyl caffeic acid, caffeoylquinic acid, and feruloylquinic acid, has succeeded in creating cell walls that have less lignin and are more easily deconstructed [37]. The COMT-deficient switchgrass was reported to have an increased dry matter digestibility [7]. Similar responses were reported for COMT-deficient tall fescue [6,15]. Although increased incorporation of ferulic acid into cell walls may lower cell wall recalcitrance, ferulic acid is thought to be one of the most inhibitory factors contributing to the biodegradability of biomass [34]. Phenolic acids and aldehydes derived from cell wall biodegradation are known fermentation inhibitors [38-40]. These cumulative responses are likely correlated with the metabolic block in the lignin pathway plus the observed lowered recalcitrance, yielding increased enzymatic sugar release from cell walls during deconstruction. Therefore, the sum of the increase of many phenolic constituents in COMT-deficient plants, including ferulic acid, its many conjugates, and the phenolic aldehydes, may explain, at least in part, the observed increase in the inhibitory nature of these plants relative to wild-type controls. When added separately to media, 
iso-sinapyl alcohol (up to $50 \mu \mathrm{g} / \mathrm{ml}$ ) and iso-sinapic acid (up to $25 \mu \mathrm{g} / \mathrm{ml}$ ) were not inhibitory to the growth of C. thermocellum cultures (data not shown). The complex changes in the cell walls of transgenic biomass that include the greater release of phenolic acids and aldehydes must be tolerated by cellulolytic microbes. However, given the significant increase in the mass yield of fermentation products with the COMT transgenic switchgrass and the observation that simple washing allows efficient fermentation by yeast and C. thermocellum [7], these transgenic biomass sources remain valuable and viable future resources for biofuels.

\section{Conclusions}

Down-regulation of the COMT activity in the lignin biosynthetic pathway of switchgrass resulted in the expected reduction in sinapyl alcohol and related metabolites, but increased phenolic acids of the lignin pathway, particularly ferulic acid, 5-hydroxyferulic acid, and ferulic acid-glycoside conjugates, and related phenolic aldehydes, including vanillin and 5-hydroxyconiferaldehyde. The accumulation of these lignin pathway related phenolic acids and aldehydes explain, in part, the observed increase in the inhibitory nature of the transgenic biomass relative to wild-type controls, following direct fermentation (with no water washing of biomass) with C. thermocellum. Additionally, down-regulation of the COMT activity revealed the presence of a novel monolignol-like metabolite, identified as iso-sinapyl alcohol and related metabolites of iso-sinapic acid, iso-sinapyl aldehyde, and iso-syringin in both non-pretreated, as well as hot water pretreated transgenic biomass. The metabolomic results suggest the increased activity of a para-methyltransferase on accumulating substrates related to 5-hydroxyconiferyl alcohol, concomitant with the reduced COMT activity, likely generates the isosinapyl alcohol related metabolites. iso-Sinapyl alcohol is considered a monolignol analog given that there was no evidence that it was integrated in cell walls, including the absence of homodimeric lignans of iso-sinapyl alcohol in the transgenic biomass, and no observable effect of iso-sinapyl alcohol on the dehydrogenative polymerization of monolignols. The emergence of a previously unknown pathway following transgenesis highlights the need to fully characterize the metabolic consequences of transgenesis by metabolomic analyses, and demonstrates transgenic biomass may have varied biological properties that require assessment.

\section{Methods}

Plant materials and hydrolysate preparation

Samples of the T1 COMT transgenic switchgrass variety Alamo and corresponding T1 wild-type were received from the Samuel Roberts Noble Foundation and have been described previously [7]. Switchgrass samples were milled in a Wiley mill through a $0.8 \mathrm{~mm}$ screen. Pretreatment was conducted using the tubular batch method from [41], except only one sand bath (Omega FSB1, Techne Co., Princeton, NJ) was used to heat the $4 \times 0.5$ inch pretreatment tubes. Biomass was soaked in nine fold excess deionized water overnight $(\sim 18 \mathrm{~h})$ and centrifuged at $11000 \mathrm{~g}$ for $5 \mathrm{~min}$ in $50 \mathrm{ml}$ disposable centrifuge tubes (Falcon) in a Sorvall Legend XTR (Thermo Scientific, Waltham, MA) centrifuge. The dry biomass solids were loaded in the pretreatment tubes, each of which holds approximately $2.5 \mathrm{~g}$, and the tubes were heated in boiling water for 2 minutes prior to heating in the sand bath at $180^{\circ} \mathrm{C}$ for $25 \mathrm{~min}$., followed by ice bath quenching. Treated biomass from each tube was used directly after the water content was determined. Anaerobic C. thermocellum fermentations were conducted in $120 \mathrm{ml}$ serum vials containing $60 \mathrm{ml}$ of MTC medium [42], and one gram hot water pretreated switchgrass at $58^{\circ} \mathrm{C}$ shaking at $150 \mathrm{rpm}$. Fermentations continued for $337 \mathrm{~h}$, but were essentially complete by $200 \mathrm{~h}$ based upon weight loss analysis [7]. Fermentation biomass composition and fermentation products were analyzed by HPLC, as described previously [42].

\section{Metabolite profiling of hydrolysates}

$250 \mu \mathrm{l}$ of thawed hydrolysate and $15 \mu \mathrm{l}$ of sorbitol $(0.1000 \mathrm{~g} / 100 \mathrm{ml}$ aqueous $)$ were transferred to a vial and concentrated to dryness under a stream of $\mathrm{N}_{2}$. The internal standard was added to correct for subsequent differences in derivatization efficiency and changes in sample volume during heating. Dried extracts were dissolved in $500 \mu \mathrm{l}$ of silylation-grade acetonitrile followed by the addition of $500 \mu \mathrm{l} \mathrm{N}$-methyl- $\mathrm{N}$-trimethylsilyltrifluoroacetamide (MSTFA) with 1\% trimethylchlorosilane (TMCS) (Thermo Scientific, Bellefonte, PA), and samples then heated for $1 \mathrm{~h}$ at $70^{\circ} \mathrm{C}$ to generate trimethylsilyl (TMS) derivatives [43]. After 1 day, $1-\mu \mathrm{l}$ aliquots were injected into an Agilent Technologies Inc. (Santa Clara, CA) 5975C inert XL gas chromatograph-mass spectrometer, fitted with an Rtx-5MS with Integra-guard (5\% diphenyl/95\% dimethyl polysiloxane) $30 \mathrm{~m} \times 250 \mu \mathrm{m} \times$ $0.25 \mu \mathrm{m}$ film thickness capillary column. The standard quadrupole GCMS was operated in the electron ionization (EI) $(70 \mathrm{eV})$ mode, with 6 full-spectrum (50-650 Da) scans per second. Gas (helium) flow was $1.33 \mathrm{ml}$ per minute with the injection port configured in the splitless mode. The injection port, MS Source, and MS Quad temperatures were $250^{\circ} \mathrm{C}, 230^{\circ} \mathrm{C}$, and $150^{\circ} \mathrm{C}$, respectively. The initial oven temperature was held at $50^{\circ} \mathrm{C}$ for $2 \mathrm{~min}$ and was programmed to increase at $20^{\circ} \mathrm{C}$ per min to $325^{\circ} \mathrm{C}$ and held for another $11 \mathrm{~min}$, before cycling back to the initial conditions. A large user-created database (>1600 spectra) of mass spectral EI fragmentation 
patterns of TMS-derivatized compounds, as well as the Wiley Registry 8th Edition combined with NIST 05 mass spectral database, were used to identify the metabolites of interest to be quantified. Peaks were reintegrated and reanalyzed using a key selected ion, characteristic $\mathrm{m} / \mathrm{z}$ fragment, rather than the total ion chromatogram, to minimize integrating co-eluting metabolites. The extracted peaks of known metabolites were scaled back up to the total ion current using predetermined scaling factors. Unidentified metabolites used the scaling factor for the internal standard (sorbitol) and were denoted by their RT as well as key $\mathrm{m} / \mathrm{z}$ fragments. The mass-to-charge ratios used as extracted ions were as follows: iso-sinapyl alcohol (354), iso-sinapic acid (368), iso-syringin (354), 5-hydroxyconiferyl alcohol-4-O-glucoside (412), 5-hydroxyconiferyl alcohol-4O-glucoside (412), 3,4-dihydroxybenzoic acid (370), xanthine (368), hypoxanthine (265), succinic acid (247), guanosine (324), uracil (241), citraconic acid (259), guanine (352), 5-hydroxyferulic acid (411), uridine (258), maleic acid (245), secoisolariciresinol (560), 5-oxo-proline (156), adenine (264), 1-O-trans-feruloylglycerol (249), vanillin (297, 194), ferulic acid (338), adenosine (236), p-coumaric acid (308), caffeic acid (396), $p$-hydroxybenzaldehyde (392, 194), coniferyl alcohol (324), 5-hydroxyconiferyl alcohol (412), coniferyl aldehyde (323), guaiacylglycerol (297), sinapyl aldehyde (353), syringylglycerol (327), p-hydroxyphenylpyruvic acid (396), syringaresinol (327), pinoresinol (502), hydroxymethylfurfural (183). Peaks were quantified by area integration and the concentrations were normalized to the quantity of the internal standard recovered, volume of sample extracted, derivatized, and injected.

\section{Statistical analyses}

Three replicate samples were analyzed per plant line. There were five wild-type lines and four COMT-deficient lines that were analyzed. Plant line was considered the experimental unit. The metabolite data were averaged by construct (COMT-deficient versus wild-type). Construct differences were analyzed by Student's t-tests with differences considered significant at $\mathrm{P} \leq 0.05$.

\section{Metabolite synthesis}

\section{Ethyl trans-3,4-dimethoxy-5-hydroxycinnamate}

To 3, 4-dimethoxy-5-hydroxybenzaldehyde (211.6 mg, $1.16 \mathrm{mmol}$ ) and $487.6 \mathrm{mg}$ ( $1.40 \mathrm{mmol}, 1.2$ equiv) of carbethoxymethylene triphenylphosphorane in a 5-ml round-bottom flask containing a magnetic stir bar was added $2.8 \mathrm{ml}$ of reagent-grade toluene. The mixture was stirred and placed in an oil bath at $80^{\circ} \mathrm{C}$ for $30 \mathrm{~min}$. After the now-homogeneous solution had cooled to room temperature, it was loaded directly onto a $10 \times 120 \mathrm{~mm}$ column of silica gel packed in 2:1 hexanes: ethyl acetate, and the product was eluted with the same solvent mixture. Product-containing fractions, identified by thin-layer chromatography analysis with visualization by UV-shadowing and staining with phosphomolybdic acid (10\% in ethanol), were combined and evaporated to dryness. The crude product (ca. $275 \mathrm{mg}$ ) was recrystallized from 10 volumes (i.e., $2.75 \mathrm{ml}$ ) of hexanes plus sufficient chloroform (ca $1.1 \mathrm{ml}$ ) to dissolve the product in boiling solvent. After removal of the mother liquor with a Pasteur pipet pulled to a capillary tip, the crystals were washed with $2 \times 1 \mathrm{ml}$ of ice-cold 3:1 hexanes:chloroform and dried in vacuo to afford $210.2 \mathrm{mg}$ (68\%) of the product. ${ }^{1} \mathrm{H}$ NMR $\left(400 \mathrm{MHz}, \mathrm{CDCl}_{3}\right) \delta 7.56(\mathrm{~d}, J=16 \mathrm{~Hz}$, $1 \mathrm{H}), 6.81(\mathrm{~d}, J=2.0 \mathrm{~Hz}, 1 \mathrm{H}), 6.64(\mathrm{~d}, J=2.0 \mathrm{~Hz}, 1 \mathrm{H})$, $6.32(\mathrm{~d}, J=16 \mathrm{~Hz}, 1 \mathrm{H}), 5.89(\mathrm{~s}, 1 \mathrm{H}), 4.26(\mathrm{q}, J=7.2 \mathrm{~Hz}$, $2 \mathrm{H}), 3.93(\mathrm{~s}, 3 \mathrm{H}), 3.89(\mathrm{~s}, 3 \mathrm{H}), 1.34(\mathrm{t}, J=7.2 \mathrm{~Hz}, 3 \mathrm{H})$; ${ }^{13} \mathrm{C}$ NMR $\left(100 \mathrm{MHz}, \mathrm{CDCl}_{3}\right) \delta 167.0,152.4,149.4,144.4$, 137.3, 130.4, 117.7, 108.0, 104.0, 61.0, 60.5, 55.9, 14.3.

\section{trans-3,4-Dimethoxy-5-hydroxycinnamyl alcohol (iso-sinapyl alcohol)}

Ethyl (E)-3, 4-dimethoxy-5-hydroxycinnamate (132.8 mg, $0.50 \mathrm{mmol}$ ) was placed in a 10 - $\mathrm{ml}$ round-bottom flask and dried azeotropically by two cycles of dissolution in toluene (ca. $2 \mathrm{ml}$ ), followed by rotary evaporation. After a stir bar was added, the flask was fitted with a rubber septum, evacuated, heated to $40^{\circ} \mathrm{C}$ for $20 \mathrm{~min}$, and then filled with dry nitrogen. Anhydrous toluene $(2.8 \mathrm{ml})$ was added, the stirred suspension was cooled to $0^{\circ} \mathrm{C}$, and DIBAL $(1.7 \mathrm{ml}$ of a $1.0 \mathrm{M}$ solution in toluene, 3.4 equiv) was added dropwise over 10 minutes. After $1 \mathrm{~h}$, TLC indicated that the starting material had been consumed. The reaction was quenched by the addition of $0.5 \mathrm{ml}$ of ethanol at $0^{\circ} \mathrm{C}$, then partitioned between water saturated with potassium bitartrate $(10 \mathrm{ml})$ and ethyl acetate $(15 \mathrm{ml})$. The aqueous layer was further extracted with $3 \times 15 \mathrm{ml}$ of ethyl acetate, and the combined organic layers were dried over sodium sulfate and filtered through Celite. After the solvent was evaporated, the crude product was purified by chromatography on a $10 \times 150 \mathrm{~mm}$ column of silica gel using 1:3 hexanes:ethyl acetate to afford the product in $>95 \%$ yield. ${ }^{1} \mathrm{H} \mathrm{NMR}\left(400 \mathrm{MHz}, \mathrm{CDCl}_{3}\right) \delta 6.66(\mathrm{~d}, \mathrm{~J}=1.9 \mathrm{~Hz}, 1$ $\mathrm{H}), 6.52(\mathrm{~d}, \mathrm{~J}=2.0 \mathrm{~Hz}, 1 \mathrm{H}), 6.49(\mathrm{dt}, \mathrm{J}=16 \mathrm{~Hz}, 1.5$ $\mathrm{Hz}, 1 \mathrm{H}), 6.26(\mathrm{dt}, \mathrm{J}=16 \mathrm{~Hz}, 5.8 \mathrm{~Hz}, 1 \mathrm{H}), 5.88$ (br s, $1 \mathrm{H}), 4.31$ (dd, J = 5.8 Hz, 1.4 Hz, $2 \mathrm{H}$ ), 3.89 $(\mathrm{s}, 3 \mathrm{H}), 3.87(\mathrm{~s}, 3 \mathrm{H}), 1.69($ br s, $1 \mathrm{H}) ;{ }^{13} \mathrm{C} \mathrm{NMR}$ $\left(100 \mathrm{MHz}, \mathrm{CDCl}_{3}\right) \delta 152.4,149.2,135.3,132.8,130.7$, 128.0, 106.4, 102.3, 63.4, 60.0, 55.7. ${ }^{1} \mathrm{H}$ NMR data matched those previously reported [25].

\section{iso-Syringin}

iso-Sinapyl alcohol (5.6 mg) and acetobromo- $\alpha-\mathrm{D}$ glucose $(11.3 \mathrm{mg})$ were dissolved in anhydrous methanol and allowed to stir under an inert atmosphere in a 
reacti-vial. Sodium methoxide (0.5 $\mathrm{M}$ in methanol) was slowly added dropwise by syringe until the solution was $\mathrm{pH}$ 9.5-10. The reaction was monitored by TLC and the $\mathrm{pH}$ was checked after several hours. Additional sodium methoxide was added to maintain $\mathrm{pH}$. The reaction was allowed to stir for 18 hours at room temperature and an aliquot was removed, evaporated, TMS-derivatized, and analyzed by GCMS, as outlined above.

\section{Lignan generation}

Oxidation of iso-sinapyl alcohol was performed with silver carbonate, essentially as described by [18]. The monolignol was dissolved at $0.1 \mathrm{M}$ in 2:1 benzene:acetone. Small portions (1.5-6 mg, 5-20 mmol) of finely pulverized $\mathrm{Ag}_{2} \mathrm{CO}_{3}$ were distributed into reacti-vials and then weighed accurately. Appropriate volumes of monolignol solution were added to produce stoichiometries of $1: 1$ or $2: 1 \mathrm{Ag}^{+}$:monolignol, and the mixtures were stirred overnight at room temperature. Each reaction mixture was applied to a small column of silica gel $(2.5-\mathrm{cm}$ bed in a Pasteur pipet), washed through with ethyl acetate, and evaporated to dryness. GCMS analysis was performed after silylation as described under Metabolite profiling of hydrolysates.

\section{Quantum chemical computational methods}

To identify low-energy conformers of iso-sinapyl alcohol and lignans, conformational scans were performed using the MM3 force field [44], as implemented in the Tinker suite of programs [45]. The ten lowest-energy conformers for each species were then optimized at the B3LYP/6-31 + G(d,p) level of theory [46,47] using the program NWChem [48]. For iso-sinapyl radical, the O5 hydrogen was removed from the corresponding alcohol conformers and the structures were re-optimized using B3LYP. The single lowest-energy conformer for each species was then re-optimized using the $\omega \mathrm{B} 97 \mathrm{X}-\mathrm{D}$ range-separated hybrid density functional with empirical dispersion corrections [49] as implemented in the program Gaussian09 [50] with the 6-31 + G(d,p) basis set. Vibrational frequencies were computed to confirm that all optimized structures were true minima. Electron spin densities based on Mulliken population analyses were used to quantify the degree of unpaired spin at various sites in the radicals, and reaction enthalpies were computed to assess the favorability of various radical conjugations. For the reaction enthalpies, corrections for basis set superposition error were included using the counterpoise method [51]. All energies were calculated for the gas phase.

\section{Determination of the effect of iso-sinapyl alcohol on dehydrogenative polymerization}

The horseradish peroxidase (HRP) catalyzed dehydrogenative polymerizations (DHP) of sinapyl alcohol (SA), or combination of sinapyl alcohol and iso-sinapyl alcohol (iso-SA) were carried out in the presence of sodium azide, according to [52]. In addition, HRP-catalyzed dehydrogenative polymerizations of coniferyl alcohol (CA) or a combination of CA and iso-SA, were carried out in the absence of sodium azide, according to the socalled bulk polymerization method [53]. Isolated DHP product was then dissolved in THF $(1 \mathrm{mg} / \mathrm{ml})$, filtered through a $0.45 \mu \mathrm{m}$ filter and placed in a $2 \mathrm{ml}$ autosampler vial. The molecular weight distributions of the DHP products were then analyzed on an Agilent GPC SECurity 1200 system equipped with four Waters Styragel columns (HR1, HR2, HR4, HR6), Agilent refractive index detector and Agilent UV detector $(270 \mathrm{~nm})$, using THF as the mobile phase $(1.0 \mathrm{ml} / \mathrm{min})$ with injection volumes of $20 \mu \mathrm{l}$. A calibration curve was constructed based on eight narrow polystyrene standards ranging in molecular weight from $1.5 \times 10^{3}$ to $3.6 \times 10^{6} \mathrm{~g} / \mathrm{mol}$. Data collection and processing were performed using Polymer Standards Service WinGPC Unity software (Build 6807). Molecular weights $\left(M_{n} / M_{w}\right)$ were calculated by the software relative to the universal polystyrene calibration curve.

HRP-catalyzed dehydrogenative polymerization of sinapyl alcohol (SA): Two solutions were prepared for the polymerization. Solution A consisted of $10.5 \mathrm{mg}$ $(0.05 \mathrm{mmol})$ of SA and $1.0 \mathrm{mg}$ of HRP $\left(100 \mathrm{U} \mathrm{mg}^{-1}\right.$, Fluka) dissolved in $10 \mathrm{ml}$ of distilled water; solution $\mathrm{B}$ consisted of $3.3 \mathrm{mg}(0.05 \mathrm{mmol})$ of sodium azide dissolved in $10 \mathrm{ml}$ of $0.02 \%$ hydrogen peroxide $(0.6 \mathrm{mmol})$. Solutions A and B were gradually added to $5 \mathrm{ml}$ of sodium phosphate buffer $(0.1 \mathrm{M}, \mathrm{pH} 6.5)$ over $30 \mathrm{~min}$ at $25^{\circ} \mathrm{C}$ and allowed to stand for $24 \mathrm{~h}$. The precipitates of the resulting DHP were collected by centrifugation and washed with distilled water and dried by vacuum oven (4.9 mg). HRP-catalyzed dehydrogenative polymerization of 4:1 SA and iso-SA: Two solutions were prepared for the polymerization. Solution A consisted of SA $(8.4 \mathrm{mg}$, $0.04 \mathrm{mmol})$ and iso-SA $(2.1 \mathrm{mg}, 0.01 \mathrm{mmol})$ and $1.0 \mathrm{mg}$ of HRP, and solution B were prepared as above. Solutions $\mathrm{A}$ and $\mathrm{B}$ were gradually added as above, and the precipitates of the resulting DHP were collected as above $(5.1 \mathrm{mg})$. HRP-catalyzed dehydrogenative polymerization of CA: Two solutions were prepared for the polymerization. Solution A consisted of CA $(8.5 \mathrm{mg}$, $0.05 \mathrm{mmol}$ ) and $1.0 \mathrm{mg}$ of HRP, and solution B were prepared as above. Solutions A and B were gradually added as above, and the precipitates of the resulting DHP were collected as above $(5.7 \mathrm{mg})$. HRP-catalyzed dehydrogenative polymerization of 4:1 CA and iso-SA: Two solutions were prepared for the polymerization. Solution A consisted of CA $(6.8 \mathrm{mg}, 0.04 \mathrm{mmol})$ and iso-SA (2.1 mg, $0.01 \mathrm{mmol}$ ) and $1.0 \mathrm{mg}$ of HRP, and solution B were prepared as above. Solutions A and B 
were gradually added and the precipitates of the resulting DHP were collected, as above $(4.2 \mathrm{mg})$.

\section{Additional file}

\section{Additional file 1: Optimized geometries for iso-sinapyl alcohol and} iso-sinapyl radical.

\section{Abbreviations}

COMT: Caffeic acid 3-O-methyltransferase EC 2.1.1.68; GCMS: Gas chromatography-mass spectrometry; H: Hydroxyphenyl; G: Guaiacyl; S: Syringyl; RT: Retention time; DIBAL: Diisobutylaluminum hydride; IEMT: iso-eugenol 4-O-methyltransferase EC 2.1.1.146; 4CL: 4-coumarate-CoA ligase EC 6.2.1.12; F5H: Ferulate-5-hydroxylase EC 1.14.-.-; $\mathrm{M}^{+}$: Molecular ion; $\mathrm{m} / \mathrm{z}$ : Mass-to-charge ratio; El: Electron ionization; TMS: Trimethylsilyl; MSTFA: $\mathrm{N}$-methyl-N-trimethylsilyltrifluoroacetamide; TMCS: Trimethylchlorosilane; SA: Sinapyl alcohol; iso-SA: iso-sinapyl alcohol; CA: Coniferyl alcohol; HRP: Horseradish peroxidase; DHP: Dehydrogenative polymerization; THF: Tetrahydrofuran; $\bar{M}_{n}$ : Number average molecular weight; $\bar{M}_{w}$ : Weight average molecular weight.

\section{Competing interests}

The authors declare that there are no competing financial or nonfinancial interests.

\section{Authors' contributions}

TJT participated in the design of the study, carried out the experimenta work, the analysis and interpretation of data and drafted the manuscript. RFS participated in the design of the study, conducted the experimental work, contributed to the writing and editing of the manuscript. NLE participated in the design of the study and conducted the experimental work. MZM participated in data analysis and interpretation. AKS and JMP participated in the design of the study, carried out the experimental work, the data analysis, and contributed to the writing of the manuscript. JCM contributed to the writing and editing of the manuscript. RS, NJ and YP carried out the experimental work, the analysis and interpretation of data. AJR participated in the design of the study, the analysis and interpretation of data, and contributed to the writing of the manuscript. CYH carried out the experimental work and data analysis. CF and Z-YW participated in the design of the study, carried out the experimental work, and edited the manuscript. BHD participated in the design of the study and edited the manuscript. RAD and JRM conceived and participated in the design of the study, and contributed to the writing and critical revision of the manuscript. All authors read and approved the final manuscript.

\section{Acknowledgements}

The research at ORNL was funded by the BioEnergy Science Center, a U.S. Department of Energy Bioenergy Research Center supported by the Office of Biological and Environmental Research in the DOE Office of Science. This manuscript has been authored by a contractor of the U.S. Government under contract DE-AC05-00OR22725. This research was also supported by the National Science Foundation through TeraGrid resources provided by NCSA under grant numbers TG-MCA08X032, TG-MCB100173 and TGCHE090035. We thank Dr. Travis R. Quick for technical assistance.

\section{Author details}

${ }^{1}$ Biosciences Division, Oak Ridge National Laboratory, Oak Ridge, TN 37831-6341, USA. ${ }^{2}$ School of Chemistry and Biochemistry, Georgia Institute of Technology, Atlanta, GA 30332, USA. ${ }^{3}$ Forage Improvement Division, The Samuel Roberts Noble Foundation, 2510 Sam Noble Parkway, Ardmore, OK 73401, USA. ${ }^{4}$ Plant Biology Division, The Samuel Roberts Noble Foundation, 2510 Sam Noble Parkway, Ardmore, OK 73401, USA. ${ }^{5}$ BioEnergy Science Center, Oak Ridge, TN 38731, USA. ${ }^{6}$ Department of Biochemistry and Molecular \& Cellular Biology, University of Tennessee, Knoxville, TN 37996 USA.

Received: 11 June 2012 Accepted: 5 September 2012 Published: 21 September 2012

\section{References}

1. Chen F, Dixon RA: Lignin modification improves fermentable sugar yields for biofuel production. Nat Biotechnol 2007, 25:759-761.

2. Whetten R, Sederoff R: Lignin Biosynthesis. Plant Cell 1995, 7:1001-1013.

3. Zubieta C, Kota P, Ferrer J-L, Dixon RA, Noel JP: Structural basis for the modulation of lignin monomer methylation by caffeic acid/5hydroxyferulic acid 3/5-O-methyltransferase. Plant Cell 2002, 14:1265-1277.

4. Suzuki S, Sakakibara N, Li L, Umezawa T, Chiang VL: Profiling of phenylpropanoid monomers in developing xylem tissue of transgenic aspen (Populus tremuloides). J Wood Sci 2010, 56:71-76.

5. Boerjan W, Ralph J, Baucher M: Lignin biosynthesis. Ann Rev Plant Biol 2003, 54:519-546.

6. Chen L, Auh C-K, Dowling P, Bell J, Chen F, Hopkins A, Dixon RA, Wang Z-Y: Improved forage digestibility of tall fescue (Festuca arundinacea) by transgenic down-regulation of cinnamyl alcohol dehydrogenase. Plant Biotechnol J 2003, 1:437-449.

7. Fu C, Mielenz JR, Xiao X, Ge Y, Hamilton CY, Rodriguez M Jr, Chen F, Foston M, Ragauskas A, Bouton J, Dixon RA, Wang Z-Y: Genetic manipulation of lignin reduces recalcitrance and improves ethanol production from switchgrass. Proc Natl Acad Sci 2011, 108:3803-3808.

8. Lygin AV, Upton J, Dohleman FG, Juvik J, Zabotina OA, Widholm JM, Lozovaya W: Composition of cell wall phenolics and polysaccharides of the potential bioenergy crop -Miscanthus. GCB Bioenergy 2011, 3:333-345.

9. Yoshida M, Liu Y, Uchida S, Kawarada K, Ukagami Y, Ichinose H, Kaneko S, Fukuda K: Effects of cellulose crystallinity; hemicellulose; and lignin on the enzymatic hydrolysis of Miscanthus sinensis to monosaccharides. Biosci Biotechnol Biochem 2008, 72:805-810.

10. Davison BH, Drescher SR, Tuskan GA, Davis MF, Nghiem NP: Variation of S/G ratio and lignin content in a Populus family influences the release of xylose by dilute acid hydrolysis. Appl Biochem Biotechnol 2006, 130:427-435.

11. Jouanin L, Goujon T, de Nadai V, Martin MT, Mila I, Vallet C, Pollet B, Yoshinaga A, Chabbert B, Petit-Conil M, Lapierre C: Lignification in transgenic poplars with extremely reduced caffeic acid O-methyltransferase activity. Plant Phys 2000, 123:1363-1374.

12. Guo D, Chen F, Inoue K, Blount JW, Dixon RA: Downregulation of caffeic acid 3-O-methyltransferase and caffeoyl CoA 3-O-methyltransferase in transgenic alfalfa: Impacts on lignin structure and implications for the biosynthesis of $\mathrm{G}$ and S lignin. Plant Cell 2001, 13:73-88.

13. Piquemal J, Chamayou S, Nadoud I, Beckert M, Barrière Y, Mila I, Lapierre C, Rigau J, Puigdomenech P, Jauneau A, Digonnet C, Boudet AM, Goffner D, Pichon M: Down-regulation of caffeic acid $O$-methyltransferase in maize revisited using a transgenic approach. Plant Phys 2002, 130:1675-1685.

14. Goujon T, Sibout R, Pollet B, Maba B, Nussaume L, Bechtold N, Lu F, Ralph J, Mila I, Barrière Y, Lapierre C, Jouanin L: A new Arabidopsis thaliana deficient in the expression of O-methyltransferase impacts lignins and sinapoyl esters. Plant Mol Bio 2003, 51:973-989.

15. Chen L, Auh C-K, Dowling P, Bell J, Lehmann D, Wang Z-Y: Transgenic down-regulation of caffeic acid O-methyltransferase (COMT) led to improved digestibility in tall fescue (Festuca arundinacea). Funct Plant Biol 2004, 31:235-245.

16. Tu Y, Rochfort S, Liu Z, Ran Y, Griffith M, Badenhorst P, Louie GV, Bowman ME, Smith KF, Noel JP, Mouradov A, Spangenberg G: Functional analyses of caffeic acid O-methyltransferase and cinnamoyl-CoA-reductase genes from perennial ryegrass (Lolium perenne). Plant Cell 2010, 22:3357-3373.

17. Vignols F, Rigau J, Torres MA, Capellades M, Puigdomènech P: The brown midrib3 bm 3 mutation in maize occurs in the gene encoding caffeic acid O-methyltransferase. Plant Cell 1995, 7:407-416.

18. Ralph J, Lapierre C, Lu F, Marita JM, Pilate G, Van Doorsselaere J, Boerjan W, Jouanin L: NMR evidence for benzodioxane structures resulting from incorporation of 5-hydroxyconiferyl alcohol into lignins of O-methyltransferase-deficient poplars. J Agric Food Chem 2001, 49:86-91.

19. Vanholme R, Ralph J, Akiyama T, Lu F, Pazo JR, Kim H, Christensen JH, Van Reusel B, Storme V, De Rycke R, Rodhe A, Morreel K, Boerjan W: Engineering traditional monolignols out of lignin by concomitant up- 
regulation of $\mathrm{F} 5 \mathrm{H} 1$ and down-regulation of COMT in Arabidopsis. Plant $J$ 2010, 64:885-897.

20. Klinke $H B$, Thomsen $A B$, Ahring BK: Inhibition of ethanol-producing yeast and bacteria by degradation products produced during pre-treatment of biomass. Appl Microbiol Biotechnol 2004, 66:10-26.

21. Quideau S, Ralph J: Facile large-scale synthesis of coniferyl, sinapyl and p-coumaryl alcohol. J Agric Food Chem 1992, 40:1108-1110.

22. Durbeej B, Eriksson LA: A density functional theory study of coniferyl alcohol intermonomeric cross linkages in lignin - Three-dimensional structures, stabilities and the thermodynamic control hypothesis. Holzforschung 2003, 57:150-164.

23. Durbeej B, Eriksson LA: Formation of beta-O-4 lignin models - A theoretical study. Holzforschung 2003, 57:466-478.

24. Samuel R, Pu Y, Raman B, Ragauskas AJ: Structural characterization and comparision of switchgrass ball-milled lignin before and after dilute acid pretreatment. Appl Biochem Biotechnol 2010, 162:62-74.

25. Ahmed AA: Daucanes and other constituents from Ferula sinaica. Phytochemistry 1991, 30:1207-1210.

26. Arevalo C, Lotti C, Piccinelli AL, Russo M, Ruiz I, Rastrelli L: Magnoflorine and phenolic derivatives from the leaves of Croton xalapensis $\mathrm{L}$. (Euphorbiaceae). Nat Prod Commun 2009, 4:1697-1700

27. Ramos CS, Vanin SA, Kato MJ: Metabolism of (-)-grandisin from Piper solmsianum in Coleoptera and Lepidoptera species. Phytochemistry 2008, 69:2157-2161

28. Bhuiya M-W, Liu C-J: Engineering monolignol 4-O-methyltransferases to modulate lignin biosynthesis. J Biol Chem 2010, 285:277-285.

29. Funk C, Brodelius PE: Phenylpropanoid metabolism in suspension cultures of Vanilla planifolia Andr. III. Conversion of 4-methoxycinnamic acids into 4-hydroxybenzoic acids. Plant Physiol 1990, 94:102-108.

30. Marita JM, Ralph J, Lapierre C, Jouanin L, Boerjan W: NMR characterization of lignins from transgenic poplars with suppressed caffeic acid O-methyltransferase activity. J Chem Soc Perkins Trans 2001, 1:2939-2945.

31. Ishikawa T, Seki M, Nishigaya K, Miura Y, Seki H, Chen I-S, Ishii H: Studies on the chemical constituents of Xanthoxylum nitidum (Roxb.) D. C. (Fagara nitida Roxb.). III. The chemical constituents of the wood. Chem Pharm Bull 1995, 43:2014-2018.

32. Tobimatsu Y, Takano T, Kamitakahara H, Nakatsubo F: Reactivity of syringyl quinone methide intermediates in dehydrogenative polymerization I: High yield production of synthetic lignins (DHPs) in horseradish peroxidase-catalyzed polymerization of sinapyl alcohol in the presence of nucleophilic reagents. J Wood Sci 2010, 56:233-241

33. Morreel K, Ralph J, Lu F, Goeminne G, Busson R, Herdewijn P, Goeman JL, Van der Eycken J, Boerjan W, Messens E: Phenolic profiling of caffeic acid O-methyltransferase-deficient poplar reveals novel benzodioxane oligolignols. Plant Phys 2004, 136:4023-4036.

34. Du L, Yu P, Rossnagel BG, Christensen DA, McKinnon JJ: Physicochemical characteristics, hydroxycinnamic acids (ferulic acid, $p$-coumaric acid) and their ratio, and in situ biodegradability: comparison of genotypic differences among six barley varieties. J Agric Food Chem 2009, 57:4777-4783.

35. Shen H, Fu C, Xiao X, Ray T, Tang Y, Wang Z, Chen F: Developmental control of lignification in stems of lowland switchgrass variety Alamo and the effects on saccharification efficiency. BioEnergy Res 2009, 2:233-245.

36. Hatfield RD, Chaptman AK: Comparing corn types for differences in cell wall characteristics and $p$-coumaroylation of lignin. J Agic Food Chem 2009, 57:4243-4249.

37. Grabber GH, Schatz PF, Kim H, Lu F, Ralph J: Identifying new lignin bioengineering targets: 1 . Monolignol-substitute impacts on lignin formation and cell wall fermentability. BMC Plant Biol 2010, 10:114. doi:10.1186/1471-2229-10-114.

38. Hartley RD, Ford CW: Phenolic constituents of plant cell walls and wall biodegradability. In Plant Cell Wall Polymers, Biogenesis and Biodegradation. Edited by Lewis LG, Paice MG. Washington, DC: American Chemical Society; 1989:135-145.

39. Palmqvist E, Hahn-Hägerdal B: Fermentation of lignocellulosic hydrolysates. II: inhibitors and mechanisms of inhibition. Bioresour Technol 2000, 74:25-33.
40. Saha BC: Lignocellulose biodegradation and applications in biotechnology. In Lignocellulose Biodegradation, Volume 889 Edited by Saha BC, Hayashi K. Washington, DC: ACS Symposium Series; 2004:2-34

41. Yang B, Wyman CE: Dilute acid and autohydrolysis pretreatment. In Biofuels: Methods and protocols. Edited by Mielenz JR. New York: Humana Press; 2009:103-114.

42. Zhang Y-H, Lynd LR: Regulation of cellulase synthesis in batch and continuous cultures of Clostridium thermocellum. J Bacteriol 2005, 187:99-106

43. Jung HW, Tschaplinski TJ, Wang L, Glazebrook J, Greenberg JT: Priming in systemic plant immunity. Science 2009, 324:89-91.

44. Allinger NL, Yuh YH, Lii J-H: Molecular Mechanics. The MM3 force field for hydrocarbons.1. J Am Chem Soc 1989, 111:8551-8566.

45. Ponder JW, Richards FM: An efficient Newton-like method for molecular mechanics energy minimization of large molecules. J Comput Chem 1987, 8:1016-1024.

46. Becke AD: Density-functional thermochemistry. III. The role of exact exchange. J Chem Phys 1993, 98:5648-5652.

47. Lee C, Yang W, Parr RG: Development of the Colle-Salvetti correlationenergy formula into a functional of the electron density. Phys Rev B 1998, 37:785-789.

48. Valiev M, Bylaska EJ, Govind N, Kowalski K, Straatsma TP, van Dam HJJ, Wang D, Nieplocha J, Apra E, Windus TL, de Jong WA: NWChem: a comprehensive and scalable open-source solution for large-scale molecular simulations. Comput Phys Commun 2010, 181:1477-1489.

49. Chai J-D, Head-Gordon M: Long-range corrected hybrid density functionals with damped atom-atom dispersion corrections. Phys Chem Chem Phys 2008, 10:6615-6620

50. Frisch MJ, Trucks GW, Schlegel HB, Scuseria GE, Robb MA, Cheeseman JR, Scalmani G, Barone V, Mennucci B, Petersson GA, Nakatsuji H, Caricato M, Li $X$, Hratchian HP, Izmaylov AF, Bloino J, Zheng G, Sonnenberg JL, Hada M, Ehara M, Toyota K, Fukuda R, Hasegawa J, Ishida M, Nakajima T, Honda Y, Kitao O, Nakaim H, Vreven T, Montgomery JA Jr, et al: Gaussian 09, Revision A.02. Wallingford: Gaussian Inc; 2009

51. Boys SF, Bernardi F: Calculation of small molecular interactions by differences of separate total energies. Some procedures with reduced errors. Mol Phys 1970, 19:553-566.

52. Tobimatsu Y, Takano T, Kamitakahara H, Nakatsubo F: Azide ion as a quinone methide scavenger in the horseradish peroxidase-catalyzed polymerization of sinapyl alcohol. J Wood Sci 2008, 54:87-89.

53. Cathala B, Saake B, Faix O, Monties B: Evaluation of the reproducibility of the synthesis of dehydrogenation polymer models of lignin. Polym Degrad Stabil 1998, 59:65-69.

doi:10.1186/1754-6834-5-71

Cite this article as: Tschaplinski et al: Down-regulation of the caffeic acid $\mathrm{O}$-methyltransferase gene in switchgrass reveals a novel monolignol analog. Biotechnology for Biofuels 2012 5:71.

\section{Submit your next manuscript to BioMed Central and take full advantage of:}

- Convenient online submission

- Thorough peer review

- No space constraints or color figure charges

- Immediate publication on acceptance

- Inclusion in PubMed, CAS, Scopus and Google Scholar

- Research which is freely available for redistribution 